\title{
ANALISA SALURAN PENGERING BERBENTUK SILINDER PADA MESIN PENGERING PAKAN TERNAK SISTEM POMPA KALOR
}

\author{
Dunan Ginting ${ }^{1}$, Himsar Ambarita ${ }^{2}$, Farel H. Napitupulu ${ }^{3}$, A. Husein Siregar ${ }^{4}$, Andianto P. ${ }^{5}$ \\ 1,2,3,4,5 Departemen Teknik Mesin, Fakultas Teknik, Universitas Sumatera Utara \\ E-mail : dunan.ginting@ rocketmail.com
}

\begin{abstract}
ABSTRAK
Analisa ini bertujuan untuk mengatasi masalah yang dihadapai para produsen pakan ternak untuk mengeringkan pakan ternak yang sudah dicacah dalam keadaan lembab menjadi kering agar tahan lebih lama.Adapun yang menjadi tujuan pada penelitian ini adalah untuk mengetahui nilai rasio humiditas udara yang terdapat pada saluran pengering, untuk mengetahui laju perpindahan panas disaluran pengering, untuk mengetahui laju pengeringan pakan ternak, untuk mengetahui laju ekstraksi penguapan spesifik, untuk mengetahui kebutuhan energi spesifik, dan untuk mengetahui biaya yang dibutuhkan saat proses pengeringan.Sebelum pengujian dilakukan terlebih dahulu disiapkan alat dan bahan pengujian ,kemudian pakan ternak ditimbang hingga massanya 1000 gram.Pakan ternak tersebut dijatuhkan dari masuk saluran menuju keluar saluran dan ditimbang pengurangan massa yang terjadi .Hasil analisa diperoleh bahwa nilai rata -rata rasio humiditas pada masuk saluran sebesar $22,04 \mathrm{~g} / \mathrm{kg}$ dan pada keluar saluran sebesar $21,84 \mathrm{~g} / \mathrm{kg}$. Nilai laju perpindahan panas pada saluran pengering adalah $155,76 \mathrm{~W}$ dan nilai koefisien geseknya sebesar 23,1887. Nilai laju pengeringan pakan ternak pada saluran pengering adalah $0.1374 \mathrm{~kg} / \mathrm{jam}$.Nilai laju ekstraksi air spesifik adalah $0.096 \mathrm{~kg} / \mathrm{kWh}$. Konsumsi energi spesifik untuk adalah 10,407 kWh/kg.Biaya yang dibutuhkan untuk proses pengeringan adalah Rp 10.053,71,- per kilogram.
\end{abstract}

Kata kunci: Saluran pengering, rasio humiditas, perpindahan panas, laju ekstraksi, konsumsi energi .

\section{PENDAHULUAN}

Kebutuhan akan pakan ternak di Indonesia sangat tinggi mengingat komoditas peternakan sangat banyak di Indonesia. Banyaknya peternakan sangat berpengaruh terhadap kebutuhan akan pakan yang akan siap untuk di makan oleh ternak, sedangkan pakan ternak yang diproduksi industri masih bersifat basah atau lembab. Untuk itu industri harus mengeringkan hasil produksinya mengunakan sinar matahari ataupun mesin pengering.

Pakan ternak merupakan penganti makanan ternak dari alam. Pakan ternak di produksi dari industri rumahan (home industry) ataupun di produksi secara massal. Dalam setiap pruduksi, produsen pakan ternak biasanya mengeringkan hasil produksinya menggunakan sinar matahari. Jika menggunakan cahaya matahari saja hasil produksi tidak mencukupi permintaan atas pakan ternak di Indonesia. Untuk itu kebutuhan mesin pengering sangat dibutuhkan guna menunjang hasil produksi pakan ternak.

Mesin yang sering di jumpai di pasaran menggunakan alat pemanas (heater) dan alat ini menggunakan tenaga arus listrik yang sangat besar. Untuk itu penulis mencoba menggunakan alat yang tidak lajim digunakan di mesin pengering yaitu AC. Panas yang didapat untuk mengeringkan didapat dari kondensor, udara kering di keluarkan oleh evaporator AC tersebut. AC yang digunakan adalah jenis AC yang biasa di temukan di pasaran yaitu AC Polytron dengan daya $1 \mathrm{PK}$. 


\section{TINJAUAN PUSTAKA \\ Proses Pengeringan}

Pengeringan adalah proses perpindahan panas dan uap air secara simultan yang memerlukan energi panas untuk menguapkan kandungan air yang dipindahkan dari permukaan bahan yang dikeringkan oleh media pengering yang biasanya berupa panas. Proses pengeringan berlaku apabila bahan yang dikeringankan kehilangan sebahagian atau keseluruhan air yang dikandungnya. Proses utama yang terjadi pada proses pengeringan adalah penguapan. Penguapan terjadi apabila air yang dikandung oleh suatu bahan teruap, yaitu apabila panas diberikan kepada bahan tersebut.

Prinsip pengeringan biasanya akan melibatkan dua kejadian yaitu panas yang diberikan pada bahan dan air harus dikeluarkan dari bahan. Dua fenomena ini menyangkut pindah panas ke dalam dan pindah massa ke luar. Yang dimaksud dengan pindah panas adalah peristiwa perpindahan energi dari udara ke dalam bahan yang dapat menyebabkan berpindahnya sejumlah massa (kandungan air) karena gaya dorong untuk keluar dari bahan (pindah massa).

\section{Pengeringan Buatan}

Pengeringan dengan menggunakan alat pengering dimana, suhu, kelembapan udara, kecepatan udara dan waktu dapat diatur dan di awasi.

Keuntungan Pengering Buatan:

- Tidak tergantung cuaca

- Kapasitas pengeringan dapat dipilih sesuai dengan yang diperlukan

- Tidak memerlukan tempat yang luas

- Kondisi pengeringan dapat dikontrol

- Pekerjaan lebih mudah.

\section{Jenis - Jenis Pengeringan Buatan}

Berdasarkan media panasnya,

- Pengeringan adiabatis ; pengeringan dimana panas dibawa ke alat pengering oleh udara panas, fungsi udara memberi panas dan membawa air.

- Pengeringan isotermik; bahan yang dikeringkan berhubungan langsung dengan alat atau plat logam yang panas.

\section{Proses pengeringan:}

- Proses pengeringan diperoleh dengan cara penguapan air

- Dengan cara menurunkan RH dengan mengalirkan udara panas disekeliling bahan

- Proses perpindahan panas; proses pemanasan dan terjadi panas sensible dari medium pemanas ke bahan, dari permukaan bahan kepusat bahan.

- Proses perpindahan massa ; proses pengeringan (penguapan), terjadi panas laten, dari permukaan bahan ke udara

- Panas sensible ; panas yang dibutuhkan/dilepaskan untuk menaikkan /menurunkan suhu suatu benda

- Panas laten ; panas yang diperlukan untuk mengubah wujud zat dari padat kecair, cair ke gas, dst, tanpa mengubah suhu benda tersebut.

\section{Faktor faktor yang mempengaruhi pengeringan.}

Pada pengeringan selalu di inginkan kecepatan pengeringan yang maksimal. Oleh karena itu perlu dilakukan usaha- usaha untuk memercepat pindah panas dan pindah massa 
(pindah massa dalam hal ini adalah perpindahan air keluar dari bahan yang dikeringkan dalam proses pengeringan tersebut).

Ada beberapa faktor yang perlu diperhatikan untuk memperoleh kecepatan pengeringan maksimum, yaitu :
(a) Luas permukaan
(b) Suhu
(c) Kecepatan udara
(d) Kelembaban udara
(e) Tekanan
(f) Waktu.

\section{Psikometrik}

Psikometrik adalah salah satu sub bidang enginering yang khusus mempelajari sifat-sifat thermofisik campuran udara dan uap air untuk selanjutnya akan disebut "udara".Pada psikometrik udara " hanya dibedakan atas udara kering dan uap air. Meskipun udara kering masih dapat dibedakan lagi menjadi komponen gas yang terdiri dari Nitrogen,Oksigen, Karbon dioksida dan yang lainnya, tetapi pada pisikometrik semuanya diperlakukan sebagai satu unit udara kering.

Ada dua cara yang dapat digunakan untuk mendapatkan sifat-sifat thermodinamik udara, yaitu dengan menggunakan persamaan-persamaan dan dengan mengunakan grafik yang menggambarkan sifat-sifat thermodinamik udara, yang biasa disebut pysikometric chart .Dengan menggunakan grafik ini, proses-proses seperti pendinginan udara, dehumidification, dan perlakuan udara kering dapat dijelaskan dengan lebih muda. Parameterparameter dan istilah yang digunakan untuk menggambarkan sifat-sifat thermodinamik udara antara lain : Humidity ratio, relatif humidity,dry-bulb dan wet-bulb,termperatur, dwe-point temperatur,sensibel end laten heat,desity, moist volume, dan entalpi.

[1] (Ambarita,H. 2011)

\section{Rasio humiditas (hummidity ratio)}

Karena udara adalah gabungan udara kering dan uap air yang terkandung pada udara, maka humidity ratio adalah perbandingan masah uap air ( $\mathrm{mw}$ ) dan massa udara (ma) yang dirumuskan:

$$
\mathrm{W}=\frac{m_{w}}{m_{a}}
$$

Satuan dari parameter ini adalah $\mathrm{kg}$ uap air/kg udara atau gram uap air/kg udara. Dengan menggunakan persamaan gas ideal dan hukum Dalton, yang merumuskan hubungan antara kandungan gas dengan tekanan persial gas, maka rasio humiditas juga dinyatakan dengan:

$$
w=0,62198 \frac{p_{w}}{p_{a t m}-p_{w}}
$$

Dimana $p w$ adalah tekanan persial uap air dan patm adalah tekanan atmosfer. Persamaan di atas menunjukan bahwa hanya dengan mengetahui tekanan persial uap air pada temperatur tertentu, kita dapat menentukan kandungan uap air di udara.[2] (McGraw-Hill.2000). 


\section{Humiditas Relatif ( relatif humidity, atau RH)}

Parameter ini adalah perbandingan fraksi mol uap air pada udara tersebut mengalami saturasi. Berdasarkan devinisi ini, persamaan yang digunakan untuk menghitung RH adalah:

$$
R H=\frac{\text { mol }_{\text {uap }}}{\text { mol }_{\text {uap }, \text { sat }}}
$$

Sebagai catatan, pada saat saturasi fraksi mol uap air yang terkandung didalam udara adalah fraksi mol maksimum. Setelah itu uap air akan mulai mengembun, atau berubah fasa menjadi cair. Berdasarkan fakta ini, pada saat terjadi saturasi, nilai relative hummidity adalah $100 \%$ jadi diingat saat terjadi saturasi $\mathrm{RH}=100 \%$

Dengan mengurangi devenisi fraksi mol dan persamaan gas ideal,RH dapat didefenisikan sebagai berikut :

$$
R H=\frac{P_{w}}{P_{w s}}
$$

$P w s$ adalah tekanan uap saat terjadi saturasi dan merupakan fungsi dari temperatur. Persamaan yang diusul ASHER dapat digunakan untuk menghitung $P w s$ (Pa):

$\operatorname{Ln}\left(\mathrm{p}_{\mathrm{ws}}\right)=\mathrm{C}_{1 /} \mathrm{T}+\mathrm{C}_{2}+\mathrm{C}_{3} \mathrm{~T}$

$+\mathrm{C}_{4} \mathrm{~T}^{2}+\mathrm{C}_{5} \mathrm{~T}^{3}+\mathrm{C}_{6} \ln \mathrm{T} \quad$ Dimana $\mathrm{T}$ adalah temperatur mutlak dalam $\mathrm{K}$.

Konstanta $\mathrm{C}_{1}$ sampai dengan $\mathrm{C}_{6}$ dapat dilihat pada tabel 2.1 berikut:

Tabel 2.1 Temperatur mutlak

\begin{tabular}{|l|l|}
\hline $\begin{array}{l}\mathrm{C}_{1}=-5,8002206 \times \\
10^{3}\end{array}$ & $\begin{array}{l}\mathrm{C}_{4}=4,1764768 \\
\times 10^{-5}\end{array}$ \\
\hline $\mathrm{C}_{2}=1,3914993 \mathrm{x}$ & $\begin{array}{l}\mathrm{C}_{5}=-1,4452093 \times \\
10^{-8}\end{array}$ \\
\hline $\begin{array}{l}\mathrm{C}_{3}=-4,8640239 \\
\mathrm{x} 10^{-2}\end{array}$ & $\mathrm{C}_{6}=6,5459673$ \\
\hline
\end{tabular}

[3] (ASHRAE Handbook. 1997)

\section{METODOLOGI PENELITIAN}

\section{Tempat dan Waktu Studi dan Pembuatan}

Penelitian dilakukan di laboratorium Motor Bakar Departemen Teknik Mesin Universitas Sumatera Utara dan dilaksanakan selama \pm 3 bulan.

\section{Alat dan Bahan Perancangan Saluran Pengering}

Alat.

Alat yang digunakan untuk merancang saluran pengering pakan ternak sistem pompa kalor adalah :
a) Rivet
f) Gunting plat
b) Martil
g) Tang
c) Bor besi
h) Gergaji besi 

d) Grinda
i) Meter

Bahan

Bahan yang di gunakan untuk merancang saluran pengering pakan ternak sistem pompa kalor adalah:
a) Plat seng
b) Besi siku
c) Kawat
d) Glass woll
e) Aluminium foil
f) Lem dextone
g) Cat
h) Besi rang-rang
i) Elbow

Saluran Pengering pakan ternak dengan Bentuk Petak

Spesifikasi:

- Tinggi $100 \mathrm{~cm}$

- Tinggi kaki $104 \mathrm{~cm}$

- luas Penampang 40 x $40 \mathrm{~cm}$

- Ukuran pipa aluran masuk udara (in) 3 inc

- Ukuran Saluran keluar udara (out) 1 inc

- Panjang Pipa aluran Masuk (in) $50 \mathrm{~cm}$

- Panjang pipa Saluran Keluar (out) $10 \mathrm{~cm}$

- Kapasitas $1 \mathrm{~kg}$

- Bahan yang dikeringkan Daun sawit yang sudah dicacah

\section{Alat dan Bahan Dalam Melakukan Pengujian}

Alat

Peralatan yang digunakan untuk mengukur variabel-variabel penelitian, antara lain:

$\mathrm{Rh}$ (Relative Humidity) Meter

Merupakan alat ukur suhu dan kelembaban udara. Jenis $\mathrm{Rh}$ meter yang digunakan adalah EL-USB-2-LCD (High Accuracy Humidity, Temperature and Dew Point Data Logger with LCD).

Spesifikasi:

Relative Humidity:

- $\quad$ Measurement range (\%): $0-100$

- $\quad$ Repeatability (short term) $(\% \mathrm{RH}) \quad: \pm 0.1$

- Accuracy (overall error) (\%RH) : $\pm 2.0^{*} \pm 4$

- $\quad$ Internal resolution $(\% \mathrm{RH}) \quad: 0.5$

- $\quad$ Long term stability $(\% \mathrm{RH} / \mathrm{yr}) \quad: 0.5$

\section{Temperature}

Measurement range $\left({ }^{\circ} \mathrm{C} /{ }^{\circ} \mathrm{F}\right) \quad:-35 /-31-+80 /+176$ 
- $\quad$ Repeatability $\left({ }^{\circ} \mathrm{C} /{ }^{\circ} \mathrm{F}\right)$

- $\quad$ Accuracy (overall error)

- $\quad$ Internal resolution $\left({ }^{\circ} \mathrm{C} /{ }^{\circ} \mathrm{F}\right)$

Dew Point

$$
\begin{aligned}
& : \pm 0.1 / \pm 0.2 \\
& \left({ }^{\circ} \mathrm{C} /{ }^{\circ} \mathrm{F}\right) \quad: \pm 0.3 / \pm 0.6- \pm 1.5 / \pm 3 \\
& : 0.5 / 1
\end{aligned}
$$
- $\quad$ Accuracy (overall error) $\left({ }^{\circ} \mathrm{C} /{ }^{\circ} \mathrm{F}\right) \quad: \pm 1.1 / \pm 2$
Logging rate : every 10 s every $12 \mathrm{hr}$
Operating temperature range $\left.*^{* * *}\left({ }^{\circ} \mathrm{C} /{ }^{\circ} \mathrm{F}\right) \quad:-35 /-31-+80 /+176\right)$

Hot Wire Anemometer

Digunakan untuk mengukur kecepatan udara yang keluar dari mesin pengering system pompa kalor. Jenis Annemometer yang digunakan adalah Hot Wire Annemometer.

\section{Blower}

Blower digunakan untuk mentransfer udara panas dari kondensor kesaluran pengering sehingga proses pengeringan akan lebih cepat dan efektif.

\section{Blower merek TOSITA}

$$
\begin{array}{ll}
\text { - } & \text { Arus }=2 \text { amper }- \text { Ukuran }=3 \text { inc } \\
\text { - } & \text { Frekuensi }=50 / 60 \mathrm{~Hz} \quad-\text { Pase }=1 \\
\text { - } & \text { Putaran }=3000 / 3600 \mathrm{Rpm} \\
\text { - } & \text { Tegangan }=220 \text { Volt } \\
& \text { Daya }=370 \text { wat }
\end{array}
$$

Laptop

Laptop digunakan untuk memindahkan data dari Rh (Relative Humidity) Meter dan mengelolah data.

Hygrometer

Hygrometer merupakan alat ukur untuk kelembapan udara Rh (Relative Humidity) sekitar dengan sistem manual

Timbangan Digital

Timbangan digital disini berfungsi sebagai alat pengukur massa berat dalam satuan gram(gr) yaitu menimbang pakan ternak yang belum dilakukan pengeringan dan setelah dilakukan pengeringan.

Spesifiikasi alat pengering:

- Panjang $=202 \mathrm{~cm}$

- Lebar $=63 \mathrm{~cm}$

- Tinggi $=87 \mathrm{~cm}$

- Tinggi kaki $=24 \mathrm{~cm}$

- Daya $1 \mathrm{Pk}$ 
Spesifikasi saluran pengering

- Tinggi $=860 \mathrm{~cm}$

- $\quad$ Diameter pipa $=4$ inc

- $\quad$ Tebal glass wool $=2,5 \mathrm{~cm}$

\section{Bahan}

PakanTernak

Bahan yang menjadi objek pengeringan pada penelitian ini adalah pakan ternak.Pakan ternak yang akan dikeringkan merupakan pakan yang dibuat dari daun kelapa sawit yang sudah di cacah sampai halus

\section{Data Penelitian}

Adapun data yang direncakan akan dikumpulkan dan selanjutnya dilakukan analisis dalam penelitian ini antara lain adalah sebagai berikut :

1. Massa Pakan Ternak (M)

Massa dari pakan di ukur pada saat keadaan basah $\left(\mathrm{M}_{\mathrm{b}}\right)$ dan pada saat keadaan kering $\left(\mathrm{M}_{\mathrm{k}}\right)$.

2. Waktu pengeringan $(\mathrm{t})$

Waktu pengeringan yang dibutuhkan untuk mengeringkan pakan yaitu lima menit sekali pada sekali percobaan pada saat basah sampai pada saat keadaan kering (berat basah sampai berat kering).

3. Temperatur $(\mathrm{T})$

Temperatur yang di ukur adalah temperatur udara pada saat masuk ke evaporator $\left(T_{\text {in }}\right)$, keluar evaporator $\left(T_{\text {out }}\right)$, saluran masuk pengering $\left(T_{\text {in }}\right)$ dan saluran keluar pengering ( $\mathrm{T}_{\text {out }}$.

4. Kelembaban udara (Rh)

Kelembaban udara yang diukur pada titik saat masuk ke evaporator $\left(\mathrm{Rh}_{1}\right)$, keluar evaporator $\left(R h_{2}\right)$, saluran masuk pengering $\left(R h_{3}\right)$ dan saluran luar pengering $\left(R h_{4}\right)$.

5. Kecepatan aliran udara (v)

Udara yang keluar dari mesin pengering dan diukur kecepatannya.

6. Kuat arus ( I )

7. Tegangan ( V )

\section{HASIL PENGUJIAN \\ Grafik Hasil Pengujian}

Dari pengujian didapat grafik suhu masuk, suhu keluar, humiditas rasio masuk dan humiditas rasio keluar dan dew-point masuk dan dew-point keluar pada saluran pengering .Adapun grafik tersebut seperti dibawah ini : 


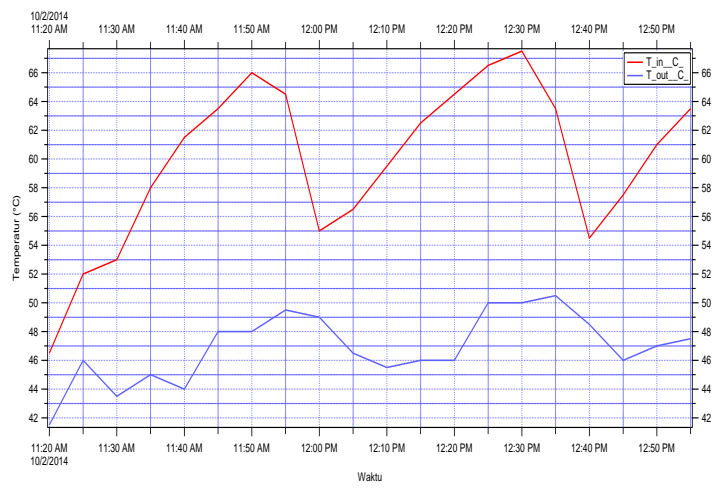

Gambar :4.1.Grafik Temperatur vs Waktu pada saluran masuk (in) dan keluar (out)

Gambar 4.1 dapat dilihat temperatur maksimum pada saluran masuk (in) adalah $67,5{ }^{\circ} \mathrm{C}$ pada waktu 12:30,sedangkan temperatur minimum adalah $46,5{ }^{\circ} \mathrm{C}$ pada waktu 11:20. Temperatur keluar (out) maksimum adalah $50,5^{\circ} \mathrm{C}$ pada waktu $12: 35$, sedangan temperature minimum adalah $41,5^{\circ} \mathrm{C}$ pada waktu $11: 20$.

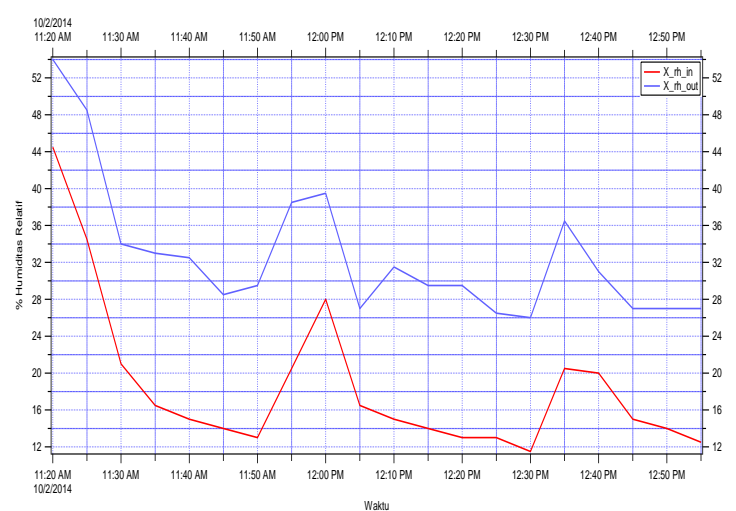

Gambar :4.2.Grafik Humiditas Relatif vs Waktu pada saluran masuk dan keluar

Gambar 4.2 dapat dilihat Humiditas Relatif saluran masuk maksimum adalah 44,5\% pada waktu 11:20,sedangkan Humiditas Relatif minimum adalah 11,5\% pada waktu 12:30.Humiditas Relatif keluar saluran maksimum adalah 54\% pada waktu 11:20, sedangan Humiditas Relatif minimum adalah 26,5\% pada waktu 12:25.

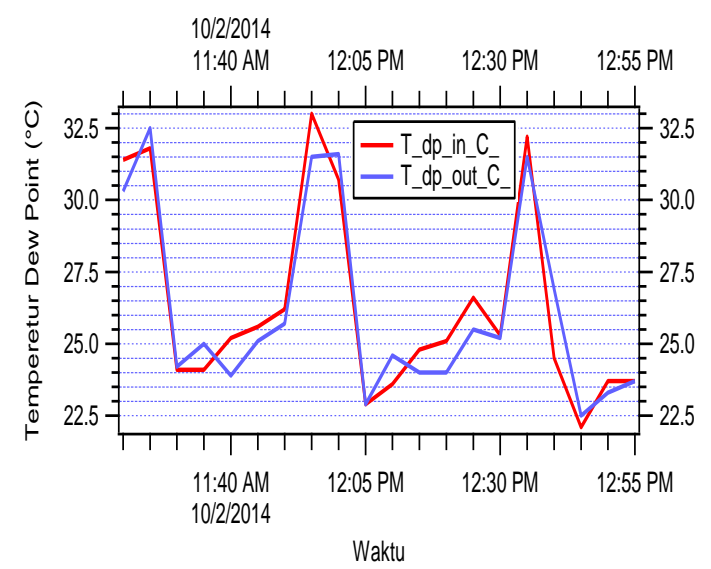

Gambar :4.3.Grafik Temperatur Dew Point pada saluran masuk dan saluran keluar vs Waktu 
Gambar 4.3. dapat dilihat temperatur dew point saluran masuk maksimum adalah $31,8{ }^{\circ} \mathrm{C}$ pada waktu 11:25 dan temperatur dew point minimum adalah $22,1{ }^{\circ} \mathrm{C}$ pada waktu $12: 45$. Tempratur dewpoint keluar saluran maksimum adalah $32,5{ }^{\circ} \mathrm{C}$ pada waktu 11:25 dan temperatur dew poin minimum adalah $24^{\circ} \mathrm{C}$ pada waktu 12:15 dan 12:20.

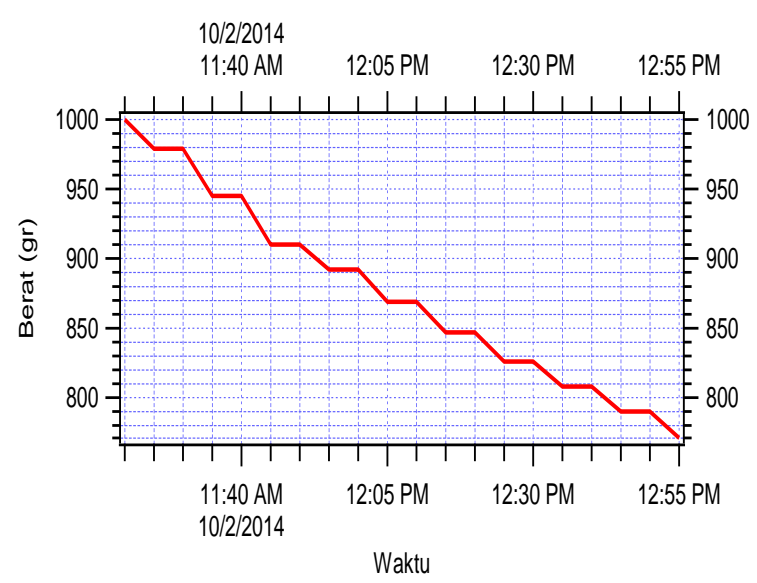

Gambar :4.4.Grafik penurunan berat pakan ternak vs Waktu

Gambar 4.4. dapat dilihat penurunan massa pakan ternak berbanding lurus terhadap waktu.Pada pukul 11:15 massa pakan ternak 1000 gram dan pada pukul 12:55 massa pakan ternak menjadi 771 gram.Maka terdapat pengurangan massa pakan ternak selama 1,6 jam sebesar 229 gram.

\section{Perhitungan Hasil Pengujian}

Perhitungan Sifat-sifat Thermodinamik Udara Pada Saluran Masuk(in).

Tekanan uap saturasi masuk saluran pengering dihitung dengan menggunakan persamaan:

$\operatorname{Ln}\left(p_{\mathrm{ws}}\right)_{\text {in }}=\mathrm{C}_{1} / \mathrm{T}_{\mathrm{in}}+\mathrm{C}_{2}+\mathrm{C}_{3} \mathrm{~T}_{\text {in }}+\mathrm{C}_{4} \mathrm{~T}^{2}$ in $+\mathrm{C}_{5} \mathrm{~T}^{3}{ }_{\text {in }}+\mathrm{C}_{6} \ln \mathrm{T}_{\text {in }}$

Dimana nilai $\mathrm{T}_{\text {in }}=50,5+273=323,5 \mathrm{~K}$

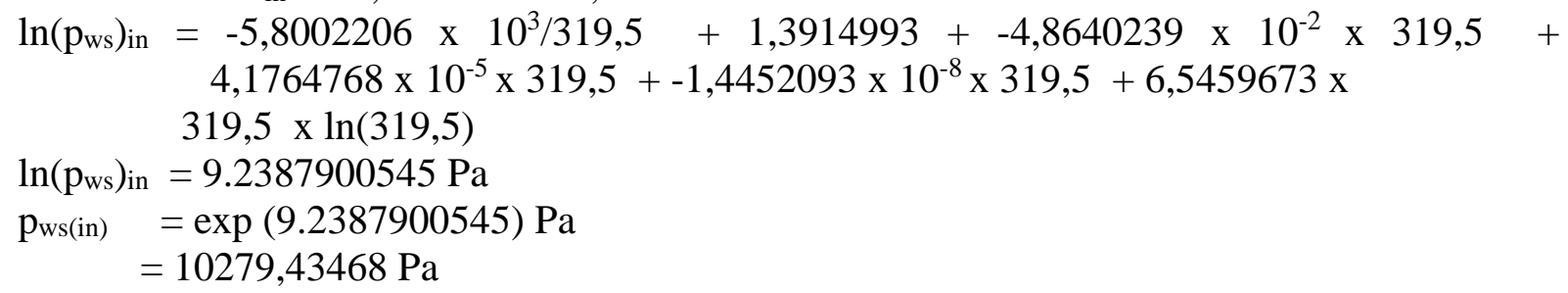

Tekanan uap air masuk saluran pengering pada udara dapat dihitung dengan persamaan:

$$
\begin{aligned}
\mathrm{p}_{\mathrm{w}(\mathrm{in})} & =\mathrm{RH}_{\text {in }} \times \mathrm{p}_{\mathrm{ws}(\mathrm{in})} \\
\mathrm{RH} & =\% \mathrm{RH}_{\text {in }} \times 0,01 \\
& =46,5 \times 0,01 \\
& =0,46 \\
\mathrm{p}_{\mathrm{w}(\mathrm{in})} & =0,46 \times 10279,43468 \mathrm{~Pa} \\
& =4574,348431 \mathrm{~Pa}
\end{aligned}
$$


Rasio humiditas masuk saluran pengering dihitung dengan persamaan :

$$
\begin{aligned}
w_{\text {in }} & =0,62198 \frac{p_{w(\text { in })}}{p_{a t m}-p_{w(i n)}} \\
& =0,62198 \frac{4574,348331}{101325-4574,348331} \\
& =0,02940707056 \mathrm{~kg} \text { uap } / \mathrm{kg} \text { udara } \\
& =29,40707056 \mathrm{~g} / \mathrm{kg}
\end{aligned}
$$

Volume spesifik udara masuk saluran pengering dihitung dengan persamaan:

$$
\begin{aligned}
v & =\frac{287,055\left(T_{\text {in }}+273\right) \times\left(1+1,6078 \times w_{\text {in }}\right)}{p_{\text {atm }}} \\
= & =\frac{287,055(319,5) \times(1+1,6078 \times 0,02940707056)}{101325} \\
& =0.947944 \mathrm{~m}^{3} / \mathrm{kg} \quad \text { Maka density }(\rho): \\
\rho & =\frac{1}{v} \\
= & \frac{1}{0.947944} \\
= & 1,054915 \mathrm{~kg} / \mathrm{m}^{3}
\end{aligned}
$$

\section{Menghitung laju Perpindahan Panas yang terjadi pada Saluran Pengering}

Dimana: saluran pengering yang digunakan berbentuk balok dengan

Panjang $\quad=8,6 \mathrm{~m}$,

Diameter $\quad=0,1016 \mathrm{~m}$

Tebal plat seng $\quad=0,0005 \mathrm{~m}$

Dilapisi glasswool setebal $=0,025 \mathrm{~m}$

$\mathrm{K}$ untuk plat seng $=166 \mathrm{w} / \mathrm{m} . \mathrm{k}$

$\mathrm{K}$ untuk glasswool $=0,046 \mathrm{w} / \mathrm{m} . \mathrm{k}$

Pada perhitungan ini diambil nilai rata-rata $T_{\text {in }}$ dan $T_{\text {out }}$ yaitu :sebesar 332,85.K. Diasumsikan Nilai udarah sekitar $\mathrm{T}_{\mathrm{o}}=304,5 \mathrm{~K}$

$$
\begin{aligned}
& \mathrm{V}=13,5 \mathrm{~m} / \mathrm{s} \\
& \begin{aligned}
\mathrm{D}_{\mathrm{h}} & =\frac{4 x \text { luas }}{\text { keliling }}=\frac{4 . A}{K} \\
& =\frac{4 . \Pi D^{2}}{\Pi D} \\
\mathrm{D}_{\mathrm{h}} & =\mathrm{D}=0,1016 \mathrm{~m}
\end{aligned}
\end{aligned}
$$

Suhu 332,85 K diproleh :

$\mu=1,966892 \times 10^{-5} \mathrm{~kg} / \mathrm{m} . \mathrm{s}$

$\operatorname{Pr}=0,715227$

$\mathrm{K}=0,02873 \mathrm{w} / \mathrm{mk}$

$\rho \quad=\frac{\mathrm{P}}{\mathrm{R} . \mathrm{T}}=\frac{1,0132 \times 10^{5}}{287(332,85)}=1,060632 \mathrm{~kg} / \mathrm{m}^{3}$ 


$$
\begin{aligned}
\operatorname{Re}=\frac{P . V . D}{\mu}= & \frac{1,060632 \times 13,5 \times 0,1016}{1,966892^{-5}} \\
& =73962,51
\end{aligned}
$$

Maka $\operatorname{Re} \geq 10.000$ (aliran Turbulen)

$\mathrm{Nu}=0,023 \operatorname{Re}^{0.8} \operatorname{Pr}^{0.4}$

$$
\begin{aligned}
& =0,023(73962,51)^{0.8}(0,715227)^{0,4} \\
& =158,0209
\end{aligned}
$$

$\mathrm{h}=\frac{\mathrm{NuK}}{\mathrm{D}}=\frac{158,0209 \times 0,02873}{0,1016}$

$\mathrm{h}=44,68 \mathrm{w} / \mathrm{m}^{2} \mathrm{k}$

hi $=44,68 \mathrm{w} / \mathrm{m}^{2} \mathrm{k}$

$$
\begin{aligned}
\mathrm{Tf} & =\frac{T s+T r}{2} \\
& =\frac{35,5+31.5}{2}=33,5{ }^{0} \mathrm{C}=306,5 \mathrm{~K}
\end{aligned}
$$

Suhu 306,5 K diproleh :

$$
\begin{aligned}
\mathrm{K} & =0,02673 \mathrm{w} / \mathrm{mk} \\
\mathrm{Pr} & =0,70943 \\
\mathrm{~V} & =16,34 \mathrm{X} 10^{-6}\left(\mathrm{~m}^{2} / \mathrm{s}\right) \\
\beta & =\frac{1}{T f}=\frac{1}{306,5} \\
& =0.00326 \\
\mathrm{Gr} & =\frac{G . \beta(T s-T r)(l)^{3}}{V \alpha} \\
& =\frac{9,8.0,00326(35,5-31,5)(8,6)^{3}}{16,34 \times 10^{-6} \times 0,02306} \\
& =215770515,6 \\
\mathrm{Ra} & =\mathrm{Gr} \times \mathrm{Pr} \\
& =215770515,6 \times 0,70943 \\
& =153082707,7 \\
N u & =0,59(\mathrm{Gr})^{1 / 4} \\
N u & =0,59 \cdot(153082707,7)^{1 / 4} \\
& =65,62715 \\
\mathrm{~h}_{0} & =N u \frac{k}{D h} \\
& =0,59 \frac{0,02673}{0,1016} \\
\mathrm{~h}_{0} & =17,265 \mathrm{w} / \mathrm{m}^{2} \mathrm{k} \\
&
\end{aligned}
$$

Tahanan termal masing-masing adalah :

$\mathrm{R}_{1}=\frac{1}{h i 2 \pi r_{1} l}=\frac{1}{44,68 \times 2 \pi 0,0508 \times 8,6}$ 


$$
\begin{aligned}
& =\frac{1}{122,58} \\
& =0,008158 \\
\mathrm{R}_{2}=\frac{\ln ^{r_{2}} / r_{1}}{2 \pi k_{a} l} & =\frac{\ln \frac{0,0513 / 0,0513}{2 \pi 166 \times 8,6}}{} \\
& =\frac{0,009794}{8965,328} \\
& =1,09248 \times 10^{-6} \\
\mathrm{R}_{3}=\frac{\ln r_{3} / r_{2}}{2 \pi k_{b} l} & =\frac{\ln ^{0,0763} / 0,0513}{2 \pi 0,046 \times 8,6} \\
& =\frac{0,396982}{2,484368} \\
& =0,159792 \\
\mathrm{R}_{4}=\frac{1}{h_{0} 2 \pi r_{3} l} & =\frac{1}{17,265 \times 2 \pi 0,0763 \times 8,6} \\
& =\frac{1}{71,145} \\
& =0,014055645
\end{aligned}
$$

Tahanan termal total adalah :

$$
\begin{aligned}
\mathrm{R}_{\text {total }} & =\mathrm{R}_{1}+\mathrm{R}_{2}+\mathrm{R}_{3}+\mathrm{R}_{4} \\
& =0,008158+1,09248 \times 10^{-6}+0,159792+0,014055645 \\
& =0,212478
\end{aligned}
$$

Maka perpindahan panas total

$$
\begin{aligned}
Q_{\text {total }} & =\frac{T_{1}-T_{0}}{R_{\text {total }}} \\
& =\frac{332,85-304,5}{0,212478} \\
& =155,76 \mathrm{~W}
\end{aligned}
$$

\section{Laju Pengeringan}

Laju pengeringan (drying rate) adalah banyaknya air yang diuapkan tiap satuan waktu atau penurunan kadar air bahan dalam satuan waktu.

Laju pengeringan dapat di hitung dengan rumus :

$$
\begin{aligned}
& \dot{m}_{d}=\frac{W_{o}-W_{f}}{t} \\
= & \frac{1 \mathrm{~kg}-0,979 \mathrm{~kg}}{0,083 \mathrm{jam}}=0,252 \mathrm{~kg} / \mathrm{jam}
\end{aligned}
$$

\section{Nilai Laju Ekstraksi Air Spesifikc (Spesific Moisture Extraction Rate)}

Nilai laju ekstraksi air spesifik atau specific moisture extraction rate (SMER) merupakan perbandingan jumlah air yang dapat diuapkan dari bahan, dengan energi listrik yang digunakan tiap jam atau energi yang dibutuhkan untuk menghilangkan kadar air pada $1 \mathrm{~kg}$ pakan ternak . Dinyatakan dalam kg/kWh.

Untuk menghitung nilai laju ekstraksi air spesifik (SMER) 5 menit pertama pengeringan diperoleh dengan rumus :

* Pada 5 menit pertama : 


$$
\begin{aligned}
\mathrm{SMER} & =\frac{\dot{\mathrm{m}}_{d}}{W_{c}+W_{b}} \\
\dot{m}_{d} & =\frac{W_{o}-W_{f}}{t} \\
& =\frac{1 \mathrm{~kg}-0,979 \mathrm{~kg}}{0,083 \mathrm{jam}} \\
& =0,252 \mathrm{~kg} / \mathrm{jam}
\end{aligned}
$$

$$
\begin{aligned}
\mathrm{Wc} & =\mathrm{V}_{\mathrm{c}} \times \mathrm{I}_{\mathrm{c}} \\
& =220 \times 4,5 \\
& =990 \text { watt }=0,99 \mathrm{~kW}
\end{aligned}
$$

$$
\begin{aligned}
\mathrm{Wb} & =\mathrm{V}_{\mathrm{b}} \times \mathrm{I}_{\mathrm{b}} \\
& =220 \times 2 \\
& =440 \text { watt }=0,44 \mathrm{~kW}
\end{aligned}
$$

$$
\begin{aligned}
\text { SMER } & =\frac{\dot{\mathrm{m}}_{d}}{W_{c}+W_{b}} \\
& =\frac{0,252}{0,99+0,44} \\
& =0,176224 \mathrm{~kg} / \mathrm{kWh}
\end{aligned}
$$

\section{Konsumsi Energi Spesifik}

Energi yang dikonsumsi spesifik atau specific energy consumption (SEC) adalah perbandingan energi yang dikonsumsi dengan kandungan air yang hilang dinyatakan dalam $\mathrm{kWh} / \mathrm{kg}$.

Untuk menghitung konsumsi energi spesifik (SEC) 5 menit pertama kita menggunakan rumus sebagai berikut :

$$
\begin{aligned}
\text { SEC } & =\frac{1}{S M E R} \\
\text { SEC } & =\frac{1}{0,176224} \\
& =5,674603 \mathrm{kWh} / \mathrm{kg}
\end{aligned}
$$

\section{Biaya Pokok Produksi}

Dalam menentukan biaya produksi diperoleh dengan menggunakan persamaan energi yang dikonsumsi spesifik atau specific energy consumption (SEC) yang dinyatakan dalam $\mathrm{kWh} / \mathrm{kg}$ dikali dengan tarif dasar listrik. Untuk harga tarif dasar listrik dibebankan sebesar Rp 966 per $\mathrm{kWh}$.

[4] (http://bisnis.liputan6.com.2014)

* Pada 5 menit pertama:

Biaya Pokok Produksi

$=$ SEC $x$ Tarif dasar listrik

$=5,674603 \mathrm{kWh} / \mathrm{kg} \times \mathrm{Rp} 966,-$

$=\operatorname{Rp} 5.481,667,-$ 


\section{Kesimpulan}

Berdasarkan analisa data dan pembahasan dapat diambil kesimpulan sebagai berikut:

1. Nilai rasio humiditas rata - rata pada masuk saluran sebesar $22,04 \mathrm{~g} / \mathrm{kg}$ dan nilai rasio humiditas rata-rata pada keluar saluran adalah sebesar $21,84 \mathrm{~g} / \mathrm{kg}$.

2. Nilai laju perpindahan panas pada saluran pengering pakan ternak berbentuk silinder sepanjang 8,6 m adalah 155,76 W dan nilai koefisien geseknya sebesar 23,1887.

3. Nilai laju pengeringan pakan ternak pada saluran pengering berbentuk silinder sepanjang $8,6 \mathrm{~m}$ dalam 10 kali pengujian adalah $0.1374 \mathrm{~kg} / \mathrm{jam}$.

4. Nilai laju ekstraksi air spesifik (Spesific Moisture Extraction Rate) saat proses pengeringan yang berlangsung selama 1,6 jam adalah $0.096 \mathrm{~kg} / \mathrm{kWh}$.

5. Konsumsi energi spesifik (Spesific Energi Consumption) untuk mesin pengering pakan ternak sistem pompa kalor dengan daya 1 PK selama 1,6 jam saat proses pengeringan adalah $10,407 \mathrm{kWh} / \mathrm{kg}$.

6. Biaya yang dibutuhkan untuk proses pengeringan pakan ternak dengan pengering sistem pompa kalor daya 1 PK selama 1,6 jam saat proses pengeringan adalah Rp 10.053,71,per kilogram.

\section{Saran}

Berdasarkan penelitian yang telah dilakukan, penulis menyarankan beberapa hal berikut:

1. Kecepatan Blower sabaiknya dapat diatur sehingga didapat kecepatan paling efektif untuk proses pengeringan.

2. Perlunya dibuat alat untuk menjatuhkan pakan ternak dari atas saluran agar pakan ternak yang jatuh dan waktu jatuh merata.

\section{DAFTAR PUSTAKA}

[1] (Ambarita,H. 2011)

[2] (McGraw-Hill.2000)

[3] (ASHRAE Handbook. 1997)

[4] (http://bisnis.liputan6.com.2014) 